Note

\section{Oxidation of $\boldsymbol{n}$-Pentane by a Gaseous Hydrocarbon Assimilating Mold, Scedosporium sp. A-4}

\author{
Masayuki ONODERA and \\ Nagahiro OGasawara \\ Department of Agricultural Chemistry, Faculty \\ of Agriculture, Niigata University, \\ Niigata 950-21, Japan
}

Received April 20, 1989

Scedosporium sp. A-4 can utilize $n$-alkanes $\left(\mathrm{C}_{2}\right.$ to $\left.\mathrm{C}_{5}\right)$ as sole sources of carbon and energy for growth. Previously, we reported that this organism formed acetone from propane and 2-butanone from $n$-butane, and that homologous primary and secondary alcohols, from gaseous $n$ alkanes $\left(\mathrm{C}_{2}\right.$ to $\left.\mathrm{C}_{4}\right)$, were accumulated extracellularly by resting mycelia in the presence of pyrazole, which is an inhibitor of alcohol dehydrogenase. ${ }^{1,2)}$

Colby et al. reported that a soluble methane monooxygenase from the obligate methane-utilizing bacterium, Methylococcus capsulatus (Bath), catalyzed the hydroxylation of $n$-alkanes $\left(C_{1}\right.$ to $\left.C_{8}\right)$ to the corresponding 1 - and 2-alcohols, but not to 3- or 4-alcohols. ${ }^{3)}$ Imai et al. reported that $n$-alkanes $\left(\mathrm{C}_{1}\right.$ to $\left.\mathrm{C}_{8}\right)$ were hydroxylated and oxidized to the corresponding alcohols, aldehydes, acids and ketones by whole-cell suspensions of the methaneoxidizing bacterium, $\mathrm{H}-2 .{ }^{4)}$

In this report we describe the oxidation of liquid $n$ alkanes $\left(\mathrm{C}_{5}\right.$ to $\left.\mathrm{C}_{10}\right)$ by Scedosporium sp. A-4. The Z-C and $\mathrm{M}-3$ media were described in the previous paper. ${ }^{1}$ This organism was grown at $30^{\circ} \mathrm{C}$ in a 0.51 -closed flask containing $100 \mathrm{ml}$ of Z-C medium and $n$-pentane $(0.1 \%, \mathrm{v} / \mathrm{v})$ under air with shaking for $48 \mathrm{hr}$ (seed culture). The seed culture was inoculated into a 31 -closed flask containing $500 \mathrm{ml}$ of M-3 medium and $n$-pentane $(0.1 \%, \mathrm{v} / \mathrm{v})$. The culture was grown at $30^{\circ} \mathrm{C}$ with shaking for $48 \mathrm{hr}$. Preparation of resting mycelia was described in the previous paper. ${ }^{2)}$ The mycelia $(0.1 \mathrm{~g}$ wet weight) were suspended in $2 \mathrm{ml}$ of $0.1 \mathrm{M}$ potassium phosphate $(\mathrm{pH} 7.0$, containing $10 \mathrm{~mm}$ pyrazole) in $10 \mathrm{ml}$ vials and then the vials were sealed with double-rubber stoppers. $4 \mu \mathrm{l}$ of a liquid $n$-alkane $\left(\mathrm{C}_{5}\right.$ to $\left.\mathrm{C}_{10}\right)$ was put into the vials. The vials were then incubated at $30^{\circ} \mathrm{C}$ on a shaking device at $120 \mathrm{rpm}$. After $1 \mathrm{hr}$ incubation, the reaction mixtures were filtered to remove the mycelia. A 2- $\mu$ l sample of each filtrate was removed with a syringe and assayed by flame ionization gas chromatography (GC-8A; Shimadzu, Kyoto) on a glass column $(3.0 \mathrm{~m}$ by $2.6 \mathrm{~mm})$ packed with $10 \%$ PEG1000 on 60/80 Uniport R (Gasukuro Kogyo Inc.,
Tokyo). The column temperature was maintained isothermally at $80^{\circ} \mathrm{C}$, at the nitrogen carrier gas flow rate of $37 \mathrm{~m} 1 / \mathrm{min}$. The various products of liquid $n$-alkane oxidation were identified by means of gas chromatography retention time comparison and co-chromatography with authentic standards. The amounts of the various products accumulated were determined from the peak areas using a standard curve which had been constructed with authentic standards. As shown in Fig. 1B, n-pentane was hydroxylated, yielding mixtures of 1-pentanol and 2-pentanol; no 3-pentanol was formed. The rates of conversion of $n$-pentane to 1-pentanol and 2-pentanol were 0.018 and $0.024 \mu \mathrm{mol} / \mathrm{hr}$ per mg dry mycelia, respectively. $n$-Hexane to $n$-decane were not oxidized, like methane.

An aliquot of each culture filtrate was removed with a syringe and assayed with a gas chromatography system and a gas chromatography-mass spectrometry combination system (M-60; Hitachi, Tokyo). The ion source temperature was held at $180^{\circ} \mathrm{C}$ during GC-MS runs. The mass spectra were obtained at an electron energy level of $70 \mathrm{eV}$ and an accelerating voltage level of $3.2 \mathrm{kV}$. A computer with a data processing system $(002 \mathrm{~B} 8 \mathrm{DK}$; Hitachi) was used to analyze the mass spectral data and to prepare mass chromatograms. As shown in Fig. $1 \mathrm{C}$ and 2, this organism accumulated 2-pentanone $(0.28 \mathrm{mmol} / 1)$ and 2-pentanol $(0.11 \mathrm{mmol} / 1)$ from $n$-pentane.

These and our previous data ${ }^{2)}$ demonstrated that Scedosporium sp. A-4 oxidizes $n$-alkanes $\left(\mathrm{C}_{2}\right.$ to $\left.\mathrm{C}_{5}\right)$ to the
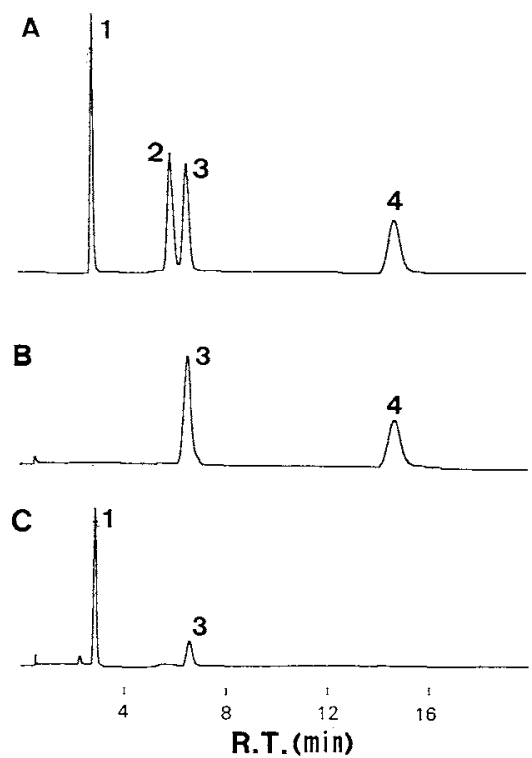

Fig. 1. Gas Chromatographic Analysis of n-Pentane Oxidation by Scedosporium sp. A-4.

A-1, 2-pentanone and 3-pentanone; A-2, 3-pentanol; A-3, 2 -pentanol; A-4, l-pentanol. B, the products of $n$-pentane oxidation by resting mycelia in the presence of pyrazole. $\mathrm{C}$, accumulated products in the culture filtrate. 

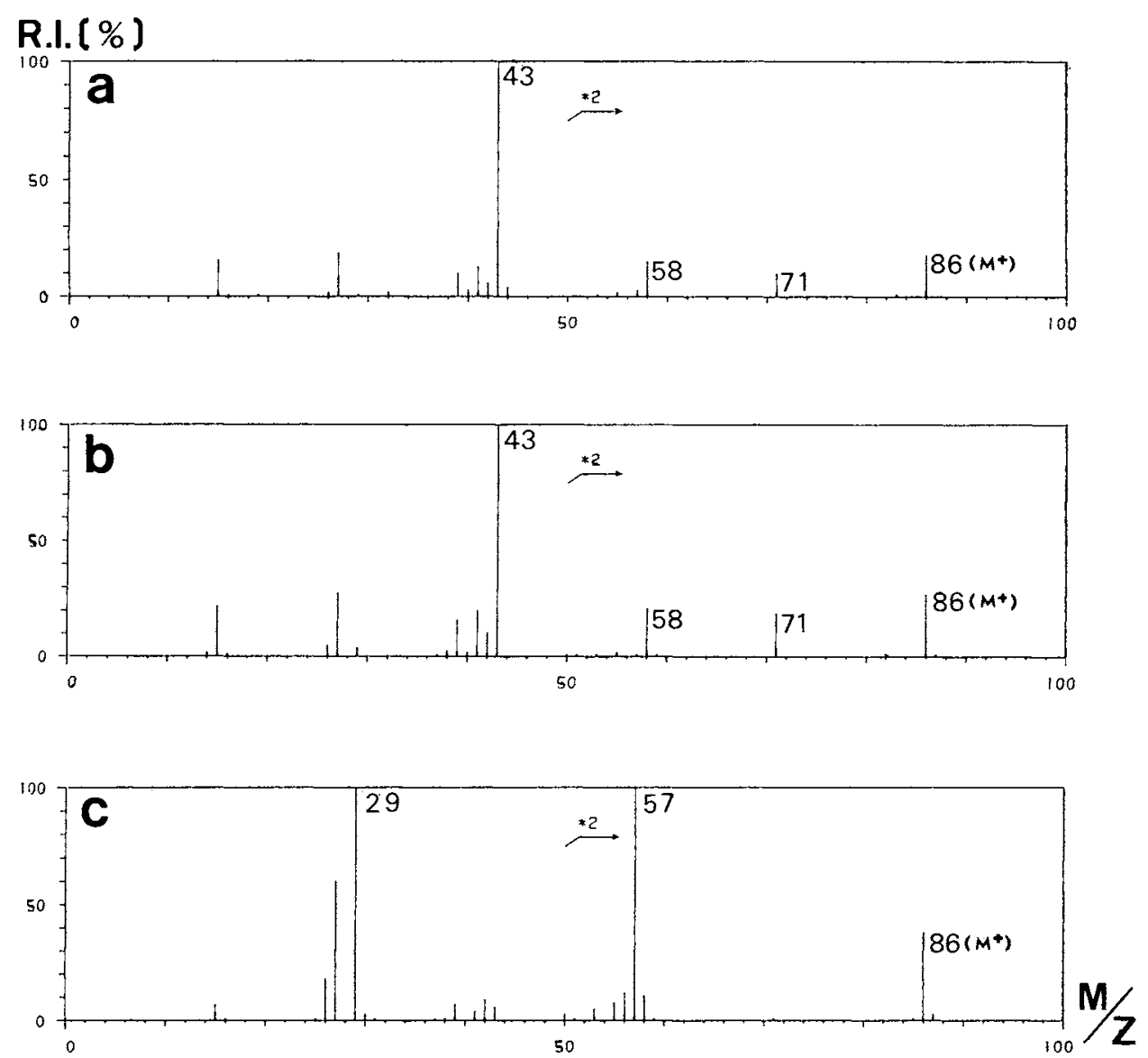

Fig. 2. Mass Spectrometric Analysis of the Culture Filtrate.

a, peak 1 material in Fig. 1C; b, 2-pentanone; c, 3-pentanone.

corresponding 1 - and 2-alcohols, but not 3-alcohols, and that methane, $n$-hexane and longer hydrocarbons (up to $\mathrm{C}_{10}$ ) are not oxidized.

Acknowledgments. We are grateful to Dr. T. Uchiyama of our laboratory for the kind advice as to $\mathrm{GC}$ MS analysis. We also wish to thank Mr. H. Sakai for his technical assistance.

\section{References}

1) M. Onodera, Y. Endo and N. Ogasawara, Agric. Biol. Chem., 53, 1431 (1989).

2) M. Onodera, Y. Endo and N. Ogasawara, Agric. Biol. Chem., 53, 1947 (1989).

3) J. Colby, D. I. Stirling and H. Dalton, Biochem. J., 165, 395 (1977).

4) T. Imai, H. Takigawa, S. Nakagawa, G.-J. Shen, T. Kodama and Y. Minoda, Appl. Environ. Microbiol., 52, 1403 (1986). 